\title{
Absent proximal left main coronary artery in association with pulmonary atresia
}

\author{
MARIE S BLACKMAN, BERNARD SCHNEIDER, HENRY M SONDHEIMER \\ From the Division of Pediatric Cardiology, Department of Pediatrics, Upstate Medical Center, \\ Syracuse, New York, and Department of Pediatrics and Radiology, Crouse-Irving Memorial Hospital, \\ New York, USA
}

SUMMARY A rare case of absence of the proximal left main coronary artery in a patient with type I pulmonary atresia is described. This is a serious and lethal aspect of a common congenital cardiac lesion. The angiographic and necropsy findings are presented. In pulmonary atresia a root aortogram should always be performed.

\section{Case report}

A 1-day-old male baby, $2.9 \mathrm{~kg}$, the product of a term pregnancy and normal delivery, presented with cardiomegaly, cyanosis, and a grade II ejection systolic murmur. The electrocardiogram showed an axis of +70 degrees and an absence of the normal neonatal right ventricular forces. There was no evidence of ischaemia. The chest $x$-ray film showed cardiomegaly with decreased pulmonary vascularity. The $\mathrm{Po}_{2}$ in 100 per cent oxygen was $29 \mathrm{mmHg}$. Percutaneous right and left heart catheterisation with serial biplane $105 \mathrm{~mm}$ spot films and balloon atrial septostomy was performed. The findings were consistent with the expected diagnosis, pulmonary atresia with intact ventricular septum and small right ventricle. There was right-to-left shunting at atrial level and a suprasystemic pressure in the right ventricle of $124 \mathrm{mmHg}$. The pulmonary artery was not entered (Fig. 1). Anteroposterior films taken one second apart at eight films per second showed pulmonary atresia, a hypoplastic right ventricle, and tricuspid regurgitation. The myocardial sinusoids filled and retrograde coronary artery opacification was noted, on the one second film not only into distal branches of the left system but also proximally to the main left coronary artery. The aorta did not opacify by retrograde coronary artery flow. The left ventricular angiogram in systole showed a poorly contracting left ventricle (Fig. 2). There was

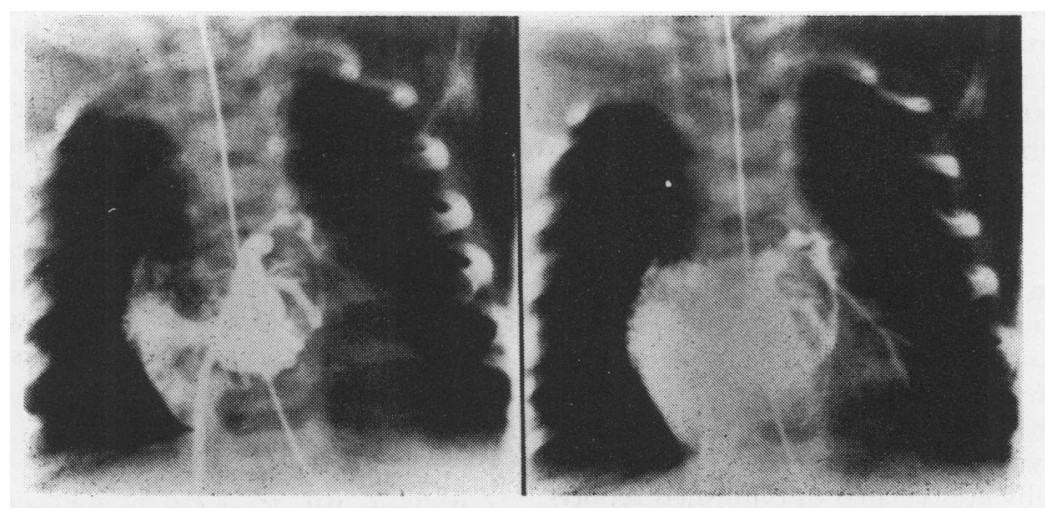

Fig. 1 Anteroposterior angiograms of the right ventricle taken one second apart at eight films per second. Note the hypoplastic right ventricle, pulmonary atresia, and tricuspid regurgitation. There are large myocardial sinusoids filling the left coronary artery system and anastomotic branches at the apex of the left ventricle from the right coronary artery. Note the absence of retrograde aortic filling. 

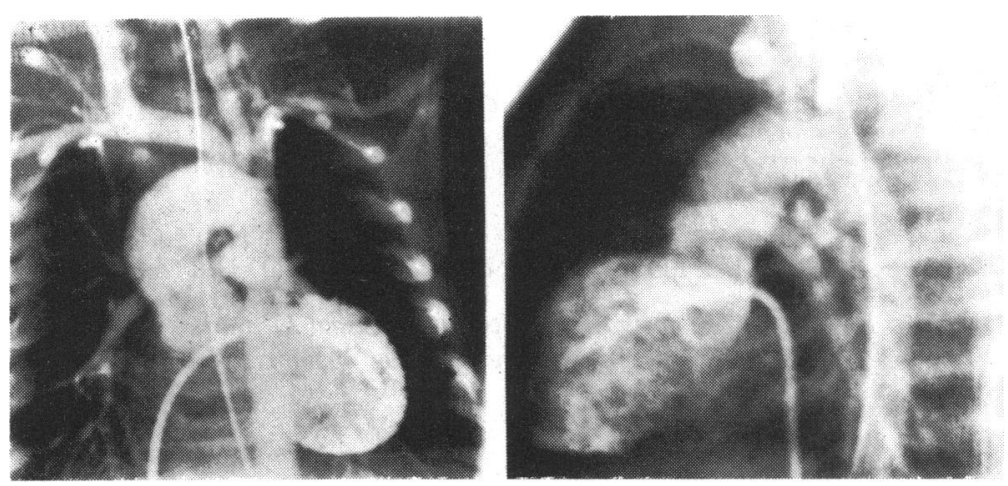

Fig. 2 Anteroposterior and lateral left ventricular angiograms during systole showing poor myccardial contractility. The small main pulmonary artery and peripheral pulmonary arteries are filling from a persistent ductus.

evidence of a persistent ductus with a kink at the pulmonary end. The pulmonary artery filled back to the level of the pulmonary valve and the peripheral pulmonary arteries were smaller than normal. The coronary artery system was not seen.

After catheterisation the patient had a sudden episode of bradycardia and died despite resuscitative measures.

Necropsy showed pulmonary valve atresia, a small muscle-bound right ventricle, a small tricuspid valve orifice, and a persistent ductus, closed on the pulmonary artery side. The right coronary artery was normal in origin. The left coronary artery system was grossly abnormal. There was a plexus of collateral vessels at the apex of the heart between right coronary artery and the distal portion of the left anterior descending coronary artery but the latter ended blindly $1 \mathrm{~cm}$ from the aorta. There was a dimple in the aorta at the usual site of the left coronary ostium. There was direct communication between myocardial sinusoids of the right ventricle and the left anterior descending coronary artery. The left circumflex branch was small but normal in distribution. Microscopical examination disclosed periarterial fibrosis and a large number of apical muscular arteries. The left anterior descending branch had distinct hypertrophy of the wall and pronounced narrowing of the lumen.

\section{Discussion}

The association of abnormal coronary arteries in patients with pulmonary atresia was first reported by Williams et al. ${ }^{1}$ This was further elaborated upon by Elliott et al. ${ }^{2}$ who clearly defined the high incidence of coronary anomalies in the group of patients with type I pulmonary valve atresia. This has not been fully appreciated in published reports. In a patient with pulmonary atresia, a competent tricuspid valve, and a small right ventricle, right ventricular hypertension is present. The sinusoids of the right ventricle contribute to the right-to-left shunt via the coronary arteries to the aorta. This may cause ischaemic myocardial changes and hinder normal diastolic coronary artery filling. ${ }^{3}$ The embryonic development of the coronary arteries suggests a dual origin, from proximal aortic buds and from distal intertrabecular spaces, myocardial sinusoids. Our case is unique in that the proximal left main coronary artery was atretic and did not communicate with either the aorta or the pulmonary artery. The proximal portion of the left main coronary failed to develop and the right ventricular myocardial sinusoids became the major source of left coronary blood flow, the rest being derived from anastomotic collaterals from the right coronary artery. A similar case involving the origin of both coronary arteries was described by Lenox et al. ${ }^{4}$

In view of the high incidence of coronary artery anomalies in patients with pulmonary atresia we recommend an aortic root angiogram during cardiac catheterisation, in addition to right and left ventricular angiograms. This will serve the dual purpose of delineating the coronary artery system, which cannot be adequately assessed on left ventricular angiograms alone, and of providing additional information regarding the distance of the pulmonary valve from the right ventricular cavity. ${ }^{5}$ Aortic root angiograms become of particular importance if retrograde aortic filling is not seen after filling of the coronary arteries from myocardial sinusoids during right ventricular angiography. The possibility of abnormal coronary arteries or persistence of fetal coronary channels should always be considered in patients with pulmonary atresia with hypoplastic right ventricle or pulmonary atresia with a competent tricuspid valve.

\section{References}

1 Williams RR, Kent GB Jr, Edwards JE. Anomalous cardiac blood vessel communicating with the right ventricle: observations in a case of pulmonary atresia with an intact ventricular septum. Arch Pathol 1951 ; 52: 480-7. 
2 Elliott LP, Adams P Jr, Edwards JE. Pulmonary atresia with intact ventricular septum. $\mathrm{Br}$ Heart $\mathcal{f}$ 1963; 25 : 489-501.

3 Freedom RM, Harrington DP. Contributions of intramyocardial sinusoids in pulmonary atresia and intact ventricular septum to a right-sided circular shunt. Br Heart $\mathcal{F} 1974$; 36: 1061-5.

4 Lenox CC, Briner J. Absent proximal coronary arteries associated with pulmonic atresia. $A m \mathcal{J}$ Cardiol 1972; 30: 666-9.

5 Freedom RM, White RI Jr, Ho CS, Gingell RL,
Hawker RE, Rowe RD. Evaluation of patients with pulmonary atresia and intact ventricular septum by double catheter technique. Am f Cardiol 1974; 33: 892-5.

Requests for reprints to Dr Marie S Blackman, Division of Pediatric Cardiology, Upstate Medical Center, 725 Irving Avenue, Syracuse, New York 13210, USA. 